\title{
Mix Learning Process in Control Engineering Course at Mechanical Engineering Department Universitas Andalas
}

\author{
Lovely Son ${ }^{1}$, Nusyirwan ${ }^{2}$ \\ \{lovelyson@eng.unand.ac.id ${ }^{1}$, nusyirwan@ft.unand.ac.id ${ }^{2}$ \} \\ ${ }^{1,2}$ Mechanical Engineering Department, Faculty of Engineering, Universitas Andalas, Padang, \\ Indonesia
}

\begin{abstract}
This study is aimed to evalute the effectiveness mix learning process between Cooperative Learning (CL) and Teacher Centered Learning (TCL) methods applied in Control Engineering course at Mechanical Engineering Department, Universitas Andalas. To conduct the learning process, the lecture material that requires an understanding of the theory delivered, students are asked to works in group discussions (CL). Meanwhile, TCL method is delivered for lecture material that requires intensive mathematical practice. The effectiveness of the learning process using combination of these two methods is showing by increasing of the achievement level and the final grade of the students in the Control Engineering course.
\end{abstract}

Keywords: Learning, TCL, CL, student, control .

\section{Introduction}

In the Control Engineering course, the basic concepts and mathematical formulations of control engineering theory are learned. One of the most important topics in Control Engineering is the systems modeling consisting of mechanical systems, electrical systems, fluid systems, and thermal systems. In this regard, understanding the basic concepts of control engineering is also determined by students' understanding of other courses such as : Mechanical Vibration, Mechatronics, Fluid Mechanics and Heat Transfer.

The use of appropriate learning techniques can improve students' understanding in the Control Engineering concept. Furthermore, the main aim of learning this course is that students are able to apply the basic concept of control engineering theory in the analysis and design of mechanical, electrical, fluid and thermal system.

Control Engineering course material is used to provide an understanding of the concepts and theories in control engineering. The Control Engineering course material is focused on: control component modeling, control system modeling, Laplace transformation, response analysis, and stability analysis.

The different in students' thinking abilities and characteristics makes it difficult for the teaching and learning process to reach the final competency formulated by the study program[1]. To overcome this problem, a new learning strategy is needed in accordance with the characteristics of the subjects contained in the Control Engineering course. 
In this research the cooperative learning (CL) combined with traditional Teacher Centered Learning (TCL) is applied to control engineering course at Mechanical Engineering, Universitas Andalas. In general, the objectives of this study are : (1) Knowing the level of acceptance (perception) of students towards the application CL and TCL methods in Control Engineering courses (2) Identifying student motivation after applying the CL and TCL method in the learning process of Control Engineering courses in the Department of Mechanical Engineering, Andalas University.

\section{Research Method}

Some steps are conducted to apply mix learning method in Control Engineering course at Andalas University as follow:

\subsection{Learning plan}

The initial step is to design a new learning plan using mix learning method by updating the old RPS into a new RPS which is more student-oriented. By using the mix learning method, the students can be more active during the learning process.

\subsection{Development of learning methods}

Students' different thinking abilities and characteristics make it difficult for the learning process to reach the final competencies formulated by the study program. To follow up on this problem, a new learning strategy is needed in accordance with the characteristics of the subjects contained in the control engineering course. Referring to the characteristics of the material / subject contained in the control engineering course, the combination of Cooperative Learning (CL) and Teacher Centered Learning (TCL) approach is considered appropriate to be developed in the learning process at Mechanical Engineering Department, Universitas Andalas. The CL+TCL method will encourage students to play an active role in exploring engineering science in solving problems related to the subject matter being taught.

\subsection{Grading}

By considering the proposed learning methods, this study performed a change in learning technique to increase the learning process quality by improving the knowledge transfer process. In the previous semester's learning plan, lectures were carried out for 14 weeks, then an assessment of homework, quizzes, Midterm Examinations (UTS) and End of Semester Examinations (UAS) were conducted. The criteria for evaluating group assignments have not been done so that the lecturer does not have time to correct student weaknesses. Therefore, this study proposes changes to the semester learning plan (RPS) of the Control Engineering course.

Based on the teaching experience in the previous years, it was seen that students did not understand the lecture material provided. This problem due to the student is difficult to understand the basic concept of system modeling that is very important in the Control Engineering course. Based on this condition, the conventional learning process using teacher centered learning is not enough to increase the student understanding and grade. 
To address the above problem, in 2019 the learning process was divided into two strategies. The learning strategy using the Cooperative Learning (CL) method was used from the beginning of the semester to the middle of the semester while the learning strategy using the TCL method by increasing the number of practice for mathematical problems was applied after the midterm to the end of the semester. The combination of methods carried out for the reasons: 1) Lecture materials before the midterm exam consist of understanding the modeling concepts that are easier to understand if done in the form of group discussions. While the lecture materials after the middle exam are more related to mathematics needs to be provided in the form of continuous practice. 2) Can be used to improve the student grade and concept understanding.

The CL method is performed by group discussion[2,3]. In this case students are divided into groups consisting of 4-5 people. Furthermore, each group is given a problem related to the material being studied. Students are asked to find solutions to these problems in groups through discussion in groups. In this case students can use references from text books and online material available on the internet. In this method the lecturer acts as a facilitator who facilitates and helps students to get solutions to the problems.

TCL method is a traditional learning technique that is usually given using lecturer presentation in front of the class. To improve student understanding, most of the materials are given in the form of exercises which are solved together with the student and lecturer. In this case, the lecturer can ask students to come to the front of the class to solve the exercises and if there are any mistakes, the lecturer helps to correct it directly [4]. Figure 1 shows the learning process scheme conducted for one semester in Control Engineering course at Mechanical Engineering Department, Universitas Andalas.

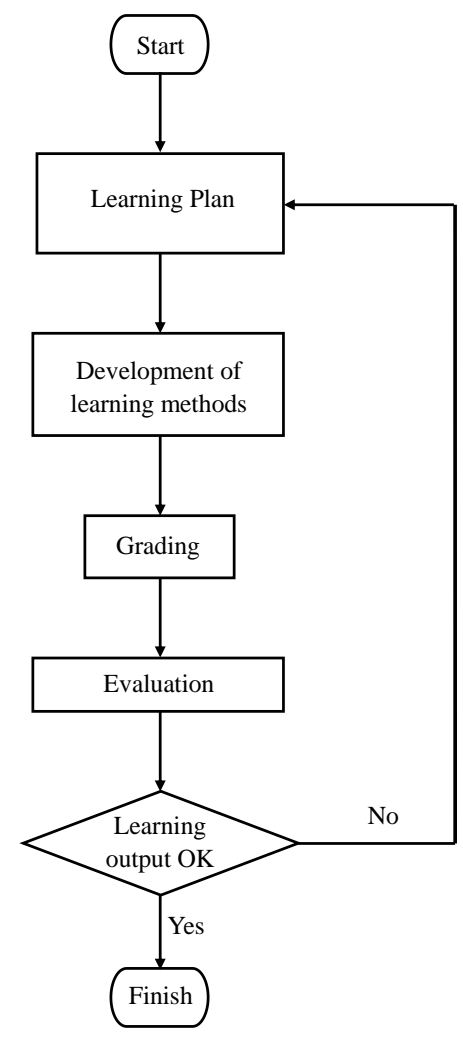


Fig. 1. Research method

\section{Results and Discussion}

Besides increasing students 'soft skills in collaborating and expressing opinions, one of the goals of group discussion is to increase students' understanding of the course material provided. The level of student satisfaction with the learning process in discussion was evaluated using a questionnaire. Figure 2 shows the results of the questionnaire which shows the level of satisfaction associated with openness in group discussions. Based on the results in Figure 2, it appears that all students gave positive responses (excellent)

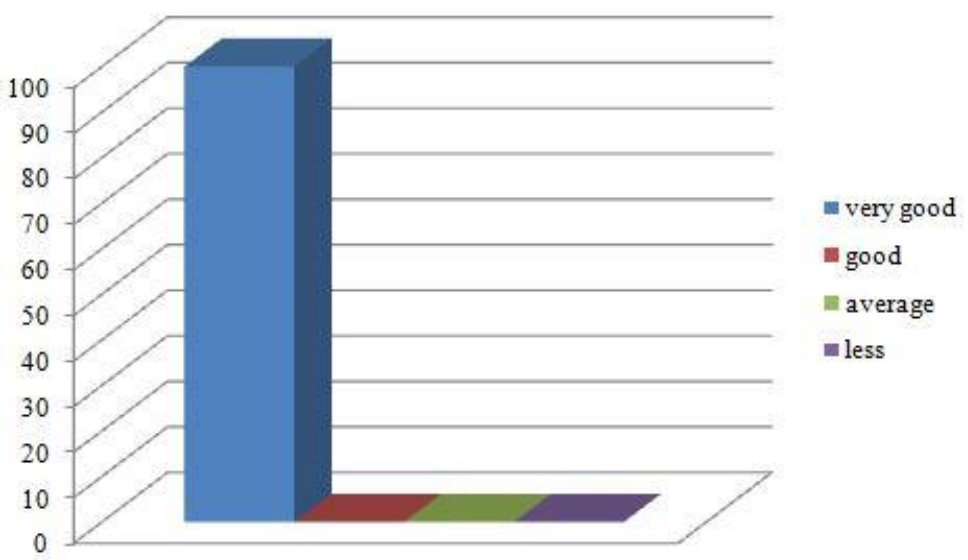

Fig. 2. Student satisfaction on using group discussion learning technique

Figure 3 shows the level of student satisfaction with respect to the mastery of teaching technology. From Figure 3, it can be seen that around $70 \%$ of students gave very good responses while the others $30 \%$ gave good responses. These results indicate that the teaching of Control Engineering courses still needs improvement in terms of teaching technology.

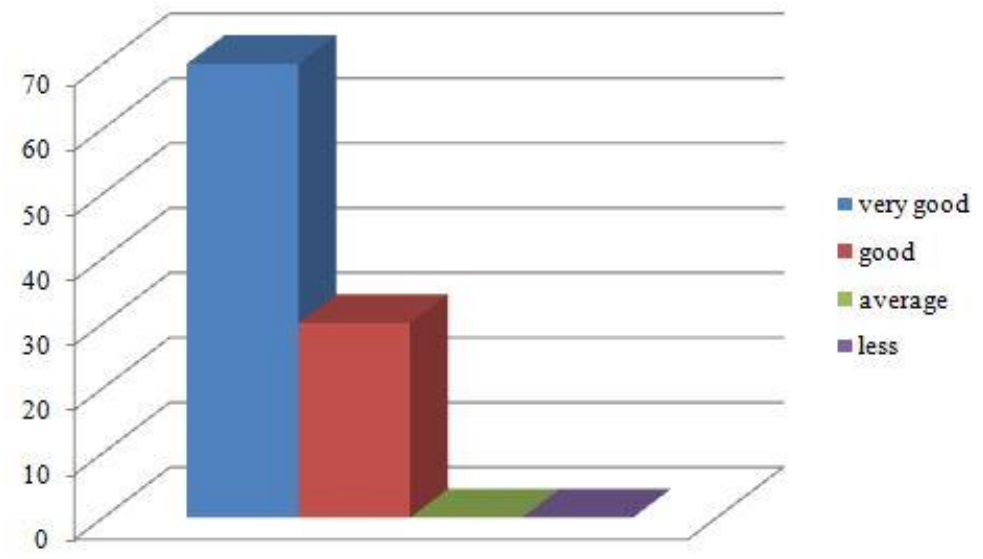


Fig. 3. Student satisfaction on using teaching technology

Figure 4 shows the distribution of grades of students taking control engineering courses. From Figure 4, it can be seen that $32.6 \%$ of students have B +, A- and A. While the number of failed students (grades D and E) is $14 \%$. Based on these results, it can be concluded that the distribution of student grades is quite good and increased compared to the previous year. The percentage of students who get B scores is quite a lot that is $23 \%$.

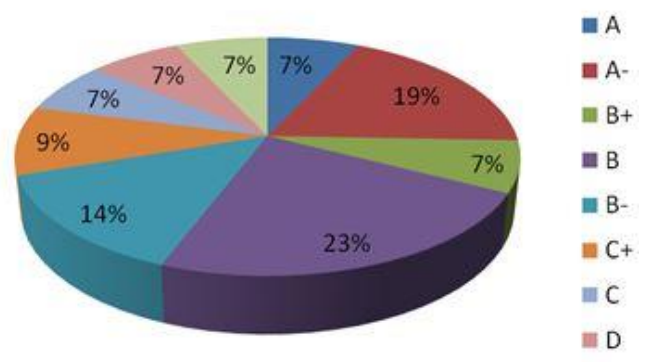

Fig. 4. Student grades distribution

The distribution of student grades in Figure 4 shows that students were quite capable of understanding the course material provided. Besides that, the level of suitability of the lecture material with SAP / Syllabus greatly determined the student's final grade. In Figure 5 the level of conformity of the lecture material is shown with the syllabus given at the beginning of the lecture. Based on the results in Figure 5, it can be shown that $90 \%$ of students gave very good responses while the others $10 \%$ gave good responses.

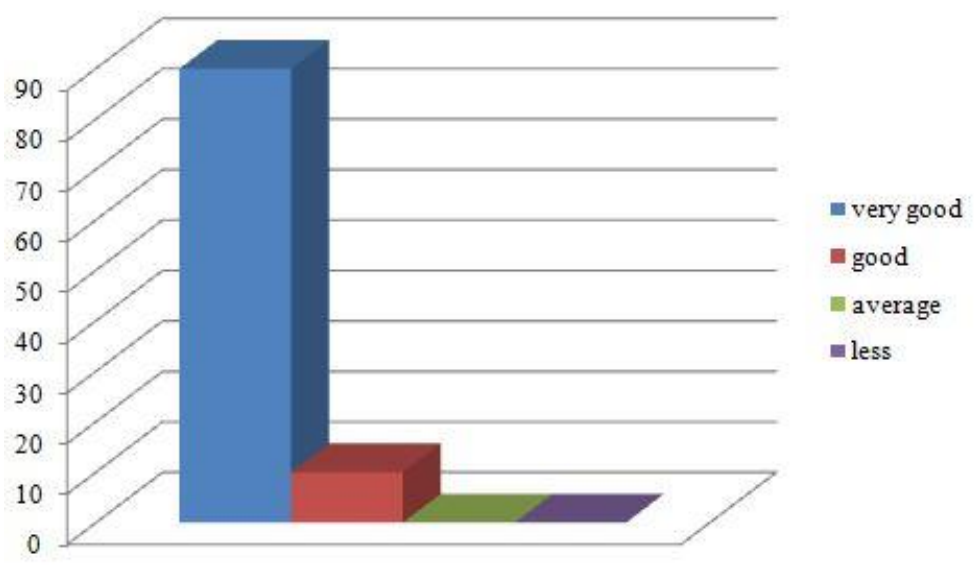

Fig. 5. Student satisfaction on conformity of the lecture materials 


\section{Summary}

Based on the results of the learning process and student responses, it can be concluded that the combination of CL and TCL methods is suitable for use in Control Engineering courses. For lecture material that requires understanding of concepts, the CL method is used [5] while for lecture material that is mostly related to mathematical formulation it is more appropriate if delivered with the TCL method by extending the practice questions in front of the class. Based on the results of the application of this combined method, there was an increase in students' understanding and grades in Control Engineering course.

\section{References}

[1] Chiu, M. M.: Adapting teacher interventions to student needs during cooperative learning. American Educational Research Journal. pp. 365-399 (2004)

[2] Chiu, M. M.: Group problem solving processes: Social interactions and individual actions. Journal for the Theory of Social Behavior. pp. 600-631 (2000)

[3] Chiu, M. M.: Flowing toward correct contributions during groups' mathematics problem solving: A statistical discourse analysis. Journal of the Learning Sciences. pp. 415-463 (2008)

[4] Cohen, E. G.: Designing group work. New York: Teacher's College (1994)

[5] Gilles, R.M., \& Adrian, F.: Cooperative Learning: The social and intellectual Outcomes of Learning in Groups. London:Farmer Press (2003) 